\title{
THE IMPACTS OF PEEL INCLUSION AND FERMENTATION TEMPERATURE ON THE BIOACTIVE COMPOUNDS, ANTIOXIDANT ACTIVITY, AND SENSORY PROPERTIES OF DRAGON FRUIT WINES
}

\author{
Thanh T. H. Le ${ }^{1,2}$, Ngoc Lieu Le $e^{1,2 \bowtie}$ \\ ${ }^{1}$ Department of Food Technology, International University \\ Quarter 6, Linh Trung Ward, Thu Duc District, Ho Chi Minh City, Vietnam \\ ${ }^{2}$ Vietnam National University, Ho Chi Minh City, Vietnam
}

\begin{abstract}
Background. Even though dragon fruit peel has more health benefits than its pulp, it is considered to be waste after fruit processing. In this study, dragon fruit peel was explored as an additional ingredient in winemaking. Materials and methods. The contents of total phenolic compounds, betacyanins and ascorbic acid, the antioxidant capacity by DPPHž method, and the level of consumer acceptability of the wines prepared from two species with and without peel were compared.

Results. The wines of the $H$. polyrhizus species contained much higher total phenolics (1.4-1.6 times), betacyanins (75-81 times), and vitamin C (2.8-3.8 times), as well as higher 1,1-diphenyl-2-picrylhydrazyl (DPPH) radical scavenging activity (1.2 times) than the wines of $H$. undatus. Although the fermentation process led to the degradation of betacyanins, it increased the total phenolics (up to 17\%), vitamin C (up to 24\%), and DPPHž scavenging activity (up to 19\%) as compared with the control when fermentation was conducted at $25^{\circ} \mathrm{C}$, which was found as the most suitable fermentation temperature to produce wines with the highest quality in terms of antioxidant content and activity. At this temperature, peel inclusion also increased these values in the wine. In addition, the sensory properties in terms of appearance and aroma could be improved in the final fermented product.

Conclusion. H. polyrhizus wine might have higher antioxidant properties than $H$. undatus wine. With a suitable fermentation temperature, peel inclusion as an ingredient could enhance these characteristics of the wine without compromising its sensory quality. This study may provide insights into fruit winemaking with higher health benefits.
\end{abstract}

Keywords: fermentation, dragon fruits, peel inclusion, betacyanins, phenolic content

\section{INTRODUCTION}

Dragon fruit, also known as pitaya or pitahaya, belongs to the Hylocereus genus of the Cactaceae family. It originates from Northern South America and is widely cultivated in Southeast Asia, especially
Vietnam (Kumar et al., 2018). There are various types of dragon fruit derived from three main species of white-fleshed fruit (Hylocereus undatus), red-fleshed fruit (Hylocereus polyrhizus), and yellow-skinned

The work was supported by International University - Vietnam National University, Ho Chi Minh city.

『nlieu@hcmiu.edu.n 
fruit (Hylocereus megalanthus), where the two former species are dominant.

The health benefits of dragon fruit have been proven in previous studies (Manihuruk et al., 2017; Qian et al., 2018). Being a good source of nutrients, dragon fruits are known to improve blood pressure and skin health, facilitate digestion, and even prevent cancer. In order to increase the fruit's marketability and avoid waste due to its short lifetime after harvesting, many researchers have utilized the fruit for the production of various derivatives such as juice (Siow and Wong, 2017; Truong and Dang, 2016), tea (Sari and Hardiyanti, 2013), and wine (Foong et al., 2012; Nguyen, 2014). Among these processing protocols, conversion of fresh dragon fruits into wine is the popular choice because fermented drinks have been demonstrated to improve overall body functions with moderate consumption (Huang et al., 2010). However, studies on dragon fruit wine are still limited. In addition, one of the potential parts of dragon fruit that has been neglected in its winemaking is the peel. Dragon fruit peels account for approximately $25 \%$ of the fruit's weight and contain a large variety of bioactive compounds (e.g., phenolics, betacyanin, vitamins, etc.). They have been proven to produce higher amounts of phenolic compounds (by 1.4 times in red-fleshed and 9.6 times in white-fleshed species) and antioxidant capacities than the pulps (Nurliyana et al., 2010). Several studies have also reported that dragon fruit peels have higher cancer cell antiproliferation than their pulps (Lourith and Kanlayavattanakul, 2013; Luo et al., 2014). The antioxidants in dragon fruit peel may include chlorogenic acid, gallic acid and quercetin (Lourith and Kanlayavattanakul, 2013). They also possess a natural appealing red color due to the presence of betacyanin compounds that have a high stability under appropriate storage conditions (Woo et al., 2011). Dragon fruit peels, however, have a bitter taste caused by the presence of certain flavonoids (Lagha-Benamrouche et al., 2018), and hence are hard to consume raw or on their own. Therefore, there is a great potential to utilize dragon fruit peels as a food ingredient in food processing, e.g., fruit winemaking. However, the use of peel during the fermentation of dragon fruit wines has not been studied.

Another winemaking concern to improve the nutritional values and health benefits of wine is the temperature of the fermentation process. Fermentation temperature significantly influences the yeast growth rate and its central metabolism (Beltran et al., 2006), which therefore governs fermentation duration and the final quality of the wine. Schwinn et al. (2019) have reported that the impact of temperature on the yeast proliferation stage can result in different maximal ethanol concentrations in wines. As temperature affects the yeasts' fermentability, it also plays an important role in controlling the microbial-induced conversion of some volatile compounds that give particular aromas in fermented drinks (Olaniran et al., 2011). Particularly if the peels of fruits are supplemented, fermentation temperature may affect the extraction and degradation of their bioactive compounds to the final fruit wine product. Therefore, this study is designed to explore the effects of peel inclusion on the antioxidant properties of wines prepared from two dragon fruit species, $H$. undatus and $H$. polyrhizus, fermented at different temperatures.

\section{MATERIALS AND METHODS}

\section{Materials and chemicals}

Ripe dragon fruits (Hylocereus undatus and Hylocereus polyrhizus) were purchased from Binh Thuan province (Vietnam). All reagents and solvents were of analytical grades and purchased from Sigma-Aldrich or Merck. The commercial wine yeast Saccharomyces cerevisiae RV100 was obtained from Angel Yeast Co., Ltd, China. Its claimed characteristics include a suitable fermentation temperature range of $10 \sim 35^{\circ} \mathrm{C}$, alcohol resistance to be more than $18 \%(\mathrm{v} / \mathrm{v})$, low production of volatile acid, and no production of sulfur dioxide and sulfur dihydride.

\section{Wine fermentation}

The two species of fresh dragon fruits were first washed under running tap water to get rid of physical dust and impurities. The outer hard peel of the fruit was then removed by knife, leaving the soft peel and pulp to be pressed by a mechanical juice presser to obtain the musts. Each type of dragon fruit must was adjusted to the soluble solid content of $22 \mathrm{~g} / 100 \mathrm{~g}$ must by glucose and then $500 \mathrm{ppm}$ of diammonium phosphate was added for yeast promotion and $200 \mathrm{ppm}$ of potassium metabisulfite for preservation. A stater culture of Saccharomyces cerevisiae RV100 was first 
rehydrated with a $20 \%(\mathrm{w} / \mathrm{v})$ glucose solution at $37^{\circ} \mathrm{C}$ before being inoculated to the musts with the ratio of $8 \times 10^{6}$ cells $/ \mathrm{mL} .200 \mathrm{~mL}$ of each sample was used for the experiment and fermentation temperatures of $20^{\circ} \mathrm{C}$ (for 21 days), 25 and $30^{\circ} \mathrm{C}$ (for 10 days) were investigated. The end-time point for wine fermentation was determined by the necessary duration for the total soluble solid content to reach about 11-12 g/100 g wine. The resultant dragon fruit wines were then centrifuged (6500 rpm at room temperature for $20 \mathrm{~min}$ ) and refrigerated at $4^{\circ} \mathrm{C}$ until further analyses within 24 hours.

\section{Analytical methods}

Determination of total phenolic content (TPC). The total phenolic content of dragon fruit wine was determined using the Folin-Ciocalteu method (Jagtap and Bapat, 2015). Dragon fruit wines were first diluted 5 times with the $10 \%(\mathrm{v} / \mathrm{v})$ Folin-Ciocalteu solution and mixed with $5 \mathrm{~mL}$ of sodium carbonate $(7.5 \%, \mathrm{w} / \mathrm{v})$ before 90 -minute incubation in the dark. The absorbance was recorded at $765 \mathrm{~nm}$ using a UV-VIS spectrophotometer. Gallic acid was used to construct a calibration curve and the results were expressed as $\mathrm{g}$ of gallic acid equivalents (GAE) per $1 \mathrm{~L}$ of alcoholic beverages $(\mathrm{g}$ GAE/L).

Determination of ascorbic acid content. Ascorbic acid content was determined spectrophotometrically using a 2,4-dinitrophenylhydrazine (DNPH) solution (Kapur et al., 2012). The dragon fruit wines were first extracted with a metaphosphoric acid - acetic acid solution and shaken gently for 30 minutes at room temperature. $4 \mathrm{~mL}$ of the extract was then mixed with $0.23 \mathrm{~mL}$ of $3 \%$ bromine water to oxidize the ascorbic acid to dehydroascorbic acid and $0.13 \mathrm{~mL}$ of $10 \%$ thiourea was added to remove the excess of bromine. Next, $1 \mathrm{~mL}$ of DNPH solution was added to form osazone. The samples were incubated at $37^{\circ} \mathrm{C}$ for 3 hours in a thermostatic water bath. After that, the samples were cooled at $4^{\circ} \mathrm{C}$ for 30 minutes before $5 \mathrm{~mL}$ of concentrated sulfuric acid was added and vortexed well. The absorbance was measured at $521 \mathrm{~nm}$ using a UV-Visible spectrophotometer. The content of ascorbic acid was calculated based on the calibration curve of $0.01 \%$ stock solution of standard L-ascorbic acid. The results obtained were expressed as $g$ of ascorbic acid per $1 \mathrm{~L}$ of sample solution ( $\mathrm{g} \mathrm{AA} / \mathrm{L})$.
Determination of betacyanin content. The betacyanin content of the dragon fruit wines was determined spectrophotometrically (Herbach et al., 2007). The samples were diluted with McIlvaine buffer $(\mathrm{pH}$ 6.5) until a maximum absorption of $1.00 \pm 0.05$ was reached. Betacyanin content $\left(B_{c}\right)$ was calculated using the following equation:

$$
B_{c}, \mathrm{mg} / \mathrm{L}=A \times F \times \mathrm{MW} \times \frac{1000}{\varepsilon \times l}
$$

where:

$A$ - absorption value at $\lambda_{\max }(537 \mathrm{~nm})$ corrected by the absorption at $600 \mathrm{~nm}$,

$F$ - dilution factor,

MW- molecular weight of betanin $(550 \mathrm{~g} / \mathrm{mol})$,

$\varepsilon-$ molar extinction coefficient of betanin $(60,000 \mathrm{~L} / \mathrm{mol} \mathrm{cm})$,

$l \quad$ - pathlength of the cuvette $(1 \mathrm{~cm})$.

Determination of antioxidant activity by 1,1-diphenyl-2-picrylhydrazyl (DPPH) assay. Antioxidant capacity was evaluated by DPPH assay (Nurliyana et al., 2010). A $0.1 \mathrm{mM}$ solution of DPPH in methanol was prepared and $3.9 \mathrm{~mL}$ of this solution was added to $0.1 \mathrm{~mL}$ of the sample at appropriate dilution. The mixture was vortexed thoroughly and allowed to stand in a dark place at room temperature for 30 minutes. $80 \%(\mathrm{v} / \mathrm{v})$ methanol solution was used as blank. The absorbance was measured at $517 \mathrm{~nm}$ using a UV-VIS spectrophotometer. The percentage of the free radical scavenging effect was calculated as follow:

$$
\text { DPPH scavenging effect, } \%=\left(1-\frac{A}{A_{0}}\right) \times 100
$$

where:

$A_{0}$ - the absorbance of the blank,

$A$ - the absorbance of the sample at $517 \mathrm{~nm}$.

Sensory test. In order to appraise consumers' perceptions of the wine products and how much they liked them, the hedonic test was chosen for the sensory evaluation. The 5-point scale test offered equal space with a neutral point for the attributes to be assessed with the following range: 1 - strongly dislike, 2 - dislike, 3 - neutral, 4 - like, 5 - strongly like (Vie et al., 1991). In this report, 40 participants aged from 20 to 60 were asked to evaluate four wine samples based 
on 4 selected attributes of appearance, aroma, taste, and overall acceptability. Comparisons were based on the Fisher's Least Significant Difference instead of the Tukey test to avoid the full control of the experimentwise type I error rate.

\section{Statistical analysis}

Statistical analysis was carried out using Minitab software (version 17.3.1). The Tukey comparison test was used to analyze the differences between the mean values of triplicate at a significance level of $95 \%$.

\section{RESULTS AND DISCUSSION}

\section{Total phenolic content of dragon fruit wines}

Phenolic compounds play a crucial role in enology because they contribute to the organoleptic properties of wine (Wang et al., 2020) and antioxidant activities (Sun et al., 2009). The phenolic content in wine depends on many factors such as fruit variety, maturation and wine technology (Kalaycığlu and Erim, 2017). In this study, the total phenolic content of the wines made from two species of dragon fruit with and without peel were evaluated at three fermenting temperatures (Table 1). The results of the initial juices squeezed from the musts were also included for detailed comparison and discussion.

Table 1 reveals that the fermentation process led to unchanged $(p>0.05)$ or slightly higher $(p<0.05)$ TPC in the wine in comparison to that in the juice when the fermenting temperature was $25^{\circ} \mathrm{C}$, while the opposite trend was observed for $20^{\circ} \mathrm{C}$ and virtually no change was noticed for $30^{\circ} \mathrm{C}$. During vinification, phenolic compounds of wine generally change significantly due to the combinative effects of their adsorption on solids, proteins or even yeasts; their extraction from the peel into the wine; their polymerization, degradation or oxidation; and their release from bound phenolic complexes with other substances induced by micro-organisms (Adetuyi and Ibrahim, 2014; Sun et al., 2009). Although high temperatures could induce high motion of molecules in the peel matrix and high diffusivity of water-soluble extractable phenolic compounds, they also promote the reactions among phenolic compounds or between them and non-phenolic compounds, leading to their alternation or precipitation. On the other hand, low temperatures slow down these reaction rates but lead to longer fermentation duration, lengthening the period for these reactions to occur (Adetuyi and Ibrahim, 2014). This explains the lower TPC contents of wines fermented at $20^{\circ} \mathrm{C}$. The results suggest that $25^{\circ} \mathrm{C}$ was the suitable fermentation temperature to obtain the highest total phenolic content, particularly for the fermentation of white-fleshed dragon fruit with $12-17 \%$ TPC increase. The improvement in the TPC of the wines as compared to their juices was ascribed to enhanced extraction of these compounds by yeast activity and production of ethanol (as their solvent) during fermentation (Liu et al., 2020; Makris et al., 2006).

\section{Betacyanin content of dragon fruit wines}

Table 2 shows a detailed comparison of betacyanin contents in the different types of wine. As expected, the

Table 1. Total phenolic content of the dragon fruit wines

\begin{tabular}{ccccc}
\hline \multirow{2}{*}{$\begin{array}{c}\text { Fermenting temperature } \\
{ }^{\circ} \mathrm{C}\end{array}$} & Thite-fleshed & white-fleshed with peel & red-fleshed & red-fleshed with peel \\
\cline { 2 - 5 } 20 & $369.3 \pm 14.7^{\mathrm{a}, \mathrm{x}}$ & $350.4 \pm 12.0^{\mathrm{a}, \mathrm{x}}$ & $575.4 \pm 12.0^{\mathrm{b}, \mathrm{x}}$ & $547.0 \pm 1.3^{\mathrm{b}, \mathrm{x}}$ \\
25 & $486.5 \pm 17.0^{\mathrm{a}, \mathrm{y}}$ & $446.8 \pm 14.7^{\mathrm{a}, \mathrm{y}}$ & $679.3 \pm 5.0^{\mathrm{b}, \mathrm{y}}$ & $640.6 \pm 11.1^{\mathrm{b}, \mathrm{y}}$ \\
30 & $439.3 \pm 1.5^{\mathrm{a}, \mathrm{z}}$ & $362.7 \pm 3.4^{\mathrm{a}, \mathrm{x}}$ & $638.7 \pm 3.3^{\mathrm{b}, \mathrm{y}}$ & $613.2 \pm 22.7^{\mathrm{b}, \mathrm{y}}$ \\
Juices & $420.2 \pm 28.3^{\mathrm{a}, \mathrm{yz}}$ & $396.5 \pm 2.8^{\mathrm{a}, \mathrm{w}}$ & $637.3 \pm 7.1^{\mathrm{b}, \mathrm{y}}$ & $617.9 \pm 2.7^{\mathrm{b}, \mathrm{y}}$ \\
\hline
\end{tabular}

Data are expressed as mean \pm standard deviation of triplicate measurements.

${ }^{\mathrm{a}-\mathrm{d}}$ The same superscript letters in the same row express that those values are not significantly different $(p>0.05)$.

${ }_{x, y, z, w}$ The same superscript letters in the same column express that those values are not significantly different $(p>0.05)$. 
Le, T. T. H., Le, N. L. (2021). The impacts of peel inclusion and fermentation temperature on the bioactive compounds, antioxidant activity, and sensory properties of dragon fruit wines. Acta Sci. Pol. Technol. Aliment., 20(3), 337-346. http://dx.doi.org/10.17306/ J.AFS.2021.0907

Table 2. Betacyanin content of the dragon fruit wines

\begin{tabular}{ccccc}
\hline \multirow{2}{*}{$\begin{array}{c}\text { Fermenting temperature } \\
{ }^{\circ} \mathrm{C}\end{array}$} & white-fleshed & white-fleshed with peel & red-fleshed & red-fleshed with peel \\
\cline { 2 - 5 } 20 & $0.61 \pm 0.00^{\mathrm{a}, \mathrm{x}}$ & $0.81 \pm 0.05^{\mathrm{b}, \mathrm{xy}}$ & $46.05 \pm 0.54^{\mathrm{c}, \mathrm{x}}$ & $51.00 \pm 0.16^{\mathrm{d}, \mathrm{x}}$ \\
25 & $0.76 \pm 0.01^{\mathrm{a}, \mathrm{y}}$ & $0.84 \pm 0.11^{\mathrm{a}, \mathrm{y}}$ & $61.63 \pm 2.17^{\mathrm{b}, \mathrm{y}}$ & $73.53 \pm 1.19^{\mathrm{c}, \mathrm{y}}$ \\
30 & $0.61 \pm 0.00^{\mathrm{a}, \mathrm{x}}$ & $0.57 \pm 0.04^{\mathrm{a}, \mathrm{x}}$ & $48.89 \pm 0.11^{\mathrm{b}, \mathrm{x}}$ & $49.47 \pm 1.03^{\mathrm{b}, \mathrm{x}}$ \\
Juices & $3.38 \pm 0.00^{\mathrm{a}, \mathrm{w}}$ & $5.91 \pm 0.01^{\mathrm{b}, \mathrm{w}}$ & $94.41 \pm 0.00^{\mathrm{c}, \mathrm{w}}$ & $114.44 \pm 0.01^{\mathrm{d}, \mathrm{w}}$ \\
\hline
\end{tabular}

Data are expressed as mean \pm standard deviation of triplicate measurements.

${ }^{\mathrm{a}-\mathrm{d}}$ The same superscript letters in the same row express that those values are not significantly different $(p>0.05)$.

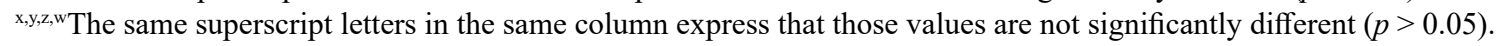

results indicated that the red-fleshed wines contained a much higher $(p<0.05)$ amount of betacyanins than the white-fleshed wines. In particular, the betacyanin contents in the white-fleshed wines were $0.6-0.8 \mathrm{mg} / \mathrm{L}$ while those of the red-fleshed wines were nearly 80 times higher. For the white-fleshed species, the addition of the peel noticeably increased the amount of betacyanins in the juices but in the wine products this elevation faded out for all samples fermented at three temperatures $(p>0.05)$. This indicated the remarkable reduction in betacyanin content during the wine fermentation. As reported by Siow and Wong (2017), high temperature or/and long processing duration could significantly reduce the amount of betacyanins. In particular, they demonstrated that the betacyanin content in red-fleshed dragon fruit juice reduced nearly $15 \%$ after storage for 2 weeks while a storage temperature of $4^{\circ} \mathrm{C}$ did not cause a significant change. Thermal betacyanin degradation could occur by isomerisation, decarboxylation, or cleavage (Azeredo, 2009), which might also be accelerated by the presence of ethanol in wine (Wybraniec and Mizrahi, 2005). Their content decline was also caused by the decrease in $\mathrm{pH}$ values after the fermentation process (Woo et al., 2011). Similar to the white-fleshed, the betacyanin content of the red-fleshed wines reduced by half of that in the initial juices. Among the three fermentation temperatures, adding the peel had the advantage of increasing the betacyanin content (11-33\%) in the wine fermented at $20^{\circ} \mathrm{C}$ for both types of wine and at $25^{\circ} \mathrm{C}$ for the redfleshed wine while $30^{\circ} \mathrm{C}$ did not produce a remarkable difference $(p>0.05)$. This implies a balance between the extraction of betacyanins from the peel and their thermal degradation at this temperature. Similar to the total phenolic content, the wines fermented at $25^{\circ} \mathrm{C}$ yielded the highest amount of betacyanins.

\section{Ascorbic acid content of dragon fruit wines}

In winemaking, ascorbic acid is not only one of the major antioxidants of the product but could provide a positive coupled effect with sulfur dioxide due to its reductive ability under wine fermentation conditions (Barril et al., 2016; Bradshaw et al., 2011). However, its content could be reduced after fermentation by oxidation reaction with the presence of metal ions and free radicals (Bradshaw et al., 2011). Table 3 displays the ascorbic acid content of different dragon fruit wines. The addition of peel for both white-fleshed and redfleshed species did not remarkably affect the ascorbic acid content of the wines $(p>0.05)$, except in the case of the red-fleshed wine fermented at $25^{\circ} \mathrm{C}(p<0.05)$. The insignificant differences in vitamin $\mathrm{C}$ content between the white-fleshed wines with and without peel supplement might be due to the negligible ascorbic acid concentration in the peel, as reported by Taganas (2015).

The amount of vitamin $\mathrm{C}$ in the red-fleshed wines was significantly higher (tripled; $p<0.05$ ) than those of the white-fleshed wines at the same fermenting temperatures. At $25^{\circ} \mathrm{C}$, for example, the vitamin $\mathrm{C}$ contents in the red-fleshed and white-fleshed wines were around 4.96-5.60 mg AA/L and 1.84-1.98 $\mathrm{mg} \mathrm{AA} / \mathrm{L}$, respectively. This was attributed to the higher vitamin $\mathrm{C}$ content in the pulp and peel of the $H$. polyrhizus species than in those of the H. undatus species (Choo and Yong, 2011). Meanwhile, fermentation on red-fleshed musts seemed to improve the vitamin $\mathrm{C}$ content (up 
Le, T. T. H., Le, N. L. (2021). The impacts of peel inclusion and fermentation temperature on the bioactive compounds, antioxidant activity, and sensory properties of dragon fruit wines. Acta Sci. Pol. Technol. Aliment., 20(3), 337-346. http://dx.doi.org/10.17306/ J.AFS.2021.0907

Table 3. Ascorbic acid content of the dragon fruit wines

\begin{tabular}{ccccc}
\hline \multirow{2}{*}{$\begin{array}{c}\text { Fermenting temperature } \\
{ }^{\circ} \mathrm{C}\end{array}$} & white-fleshed & white-fleshed with peel & red-fleshed & red-fleshed with peel \\
\cline { 2 - 4 } 20 & $1.23 \pm 0.08^{\mathrm{a}, \mathrm{x}}$ & $1.49 \pm 0.05^{\mathrm{a}, \mathrm{x}}$ & $4.47 \pm 0.10^{\mathrm{b}, \mathrm{x}}$ & $4.54 \pm 0.10^{\mathrm{b}, \mathrm{x}}$ \\
25 & $1.84 \pm 0.15^{\mathrm{a}, \mathrm{y}}$ & $1.98 \pm 0.05^{\mathrm{a}, \mathrm{y}}$ & $4.96 \pm 0.00^{\mathrm{b}, \mathrm{y}}$ & $5.60 \pm 0.10^{\mathrm{c}, \mathrm{y}}$ \\
30 & $1.24 \pm 0.09^{\mathrm{a}, \mathrm{x}}$ & $1.59 \pm 0.15^{\mathrm{a}, \mathrm{x}}$ & $4.44 \pm 0.15^{\mathrm{b}, \mathrm{x}}$ & $4.65 \pm 0.05^{\mathrm{b}, \mathrm{x}}$ \\
Juices & $2.08 \pm 0.00^{\mathrm{a}, \mathrm{y}}$ & $2.87 \pm 0.02^{\mathrm{b}, \mathrm{w}}$ & $3.92 \pm 0.01^{\mathrm{c}, \mathrm{w}}$ & $4.55 \pm 0.01^{\mathrm{b}, \mathrm{x}}$ \\
\hline
\end{tabular}

Data are expressed as mean \pm standard deviation of triplicate measurements.

${ }^{\mathrm{a}-\mathrm{d}}$ The same superscript letters in the same row express that those values are not significantly different $(p>0.05)$.

${ }^{x, y, z, w}$ The same superscript letters in the same column express that those values are not significantly different $(p>0.05)$.

to $28 \%$ ) in the wine. As reported by Branduardi et al. (2007), the anaerobic fermentation of Saccharomyces cerevisiae yeasts could increase vitamin $\mathrm{C}$ content due to their biosynthesis of L-ascorbic acid from D-glucose. A similar observation was revealed by Adetuyi and Ibrahim (2014) for the fermentation of okra seeds. All the red-fleshed wines without peel addition fermented at three temperatures showed significantly higher $(p<$ 0.05 ) amounts of vitamin $C$ than their corresponding musts, whereas among the red-fleshed wines with peel addition, only the sample made at $25^{\circ} \mathrm{C}$ exhibited a significant increase $(p<0.05)$. This, once again, supports the presumption that $25^{\circ} \mathrm{C}$ was the most suited temperature for the dragon fruit wine fermentation.

\section{Antioxidant capacity of dragon fruit wines}

Concerning the antioxidant activities of dragon fruit wines, phenolic compounds, betacyanins and vitamin
$\mathrm{C}$ all possess potent antioxidant activities. However, the correlation between their contents and activities might be not consistent. For example, some authors found no correlation between the total phenolic content and the antioxidant activities of wines (Zafrilla et al., 2003) while others reported a positive correlation between them (Derakhshan et al., 2018; Limmongkon et al., 2017). This is due to the fact that antioxidant activity depends not only on the content but also on the chemical structure of antioxidant compounds. In this study, the antioxidant activity of dragon fruit wines was evaluated by the DPPH assay, which was used to test the radical scavenging activity based on the hydrogen-donating ability of the antioxidant components present in wine. Table 4 illustrates their detailed comparison.

In comparison to the dragon fruit musts, all four corresponding types of wine fermented at $25^{\circ} \mathrm{C}$ showed

Table 4. DPPH radical scavenging activity of the dragon fruit wines

\begin{tabular}{ccccc}
\hline \multirow{2}{*}{$\begin{array}{c}\text { Fermenting temperature } \\
{ }^{\circ} \mathrm{C}\end{array}$} & Dhite-fleshed & white-fleshed with peel & red-fleshed & red-fleshed with peel \\
\cline { 2 - 4 } & $20.41 \pm 0.16^{\mathrm{a}, \mathrm{x}}$ & $21.69 \pm 0.37^{\mathrm{b}, \mathrm{x}}$ & $25.43 \pm 0.02^{\mathrm{c}, \mathrm{x}}$ & $26.09 \pm 0.08^{\mathrm{c}, \mathrm{x}}$ \\
20 & $24.61 \pm 0.32^{\mathrm{a}, \mathrm{y}}$ & $26.13 \pm 0.05^{\mathrm{b}, \mathrm{y}}$ & $30.24 \pm 0.08^{\mathrm{c}, \mathrm{y}}$ & $32.27 \pm 0.63^{\mathrm{d}, \mathrm{y}}$ \\
30 & $20.52 \pm 0.20^{\mathrm{a}, \mathrm{x}}$ & $22.17 \pm 0.28^{\mathrm{b}, \mathrm{x}}$ & $25.64 \pm 0.02^{\mathrm{c}, \mathrm{z}}$ & $26.35 \pm 0.60^{\mathrm{c}, \mathrm{z}}$ \\
Juices & $21.21 \pm 0.00^{\mathrm{a}, \mathrm{x}}$ & $21.94 \pm 0.00^{\mathrm{b}, \mathrm{x}}$ & $27.48 \pm 0.00^{\mathrm{c}, \mathrm{w}}$ & $28.95 \pm 0.00^{\mathrm{d}, \mathrm{w}}$ \\
\hline
\end{tabular}

Data are expressed as mean \pm standard deviation of triplicate measurements.

${ }^{a-d}$ The same superscript letters in the same row express that those values are not significantly different $(p>0.05)$.

${ }^{\mathrm{x}, \mathrm{y}, \mathrm{z}, \mathrm{w}}$ The same superscript letters in the same column express that those values are not significantly different $(p>0.05)$. 
a significant increase $(p<0.05)$ in antioxidant capacity (10-19\% increase). The increase in the antioxidant capacity after the fermentation process was due to the releases of phenolic compounds, vitamin C (as presented in Tables 1 and 3) and other antioxidants by the microbial hydrolysis reaction (Hur et al., 2014; Najgebauer-Lejko and Sady, 2015). This, however, did not happen in the samples fermented at $20^{\circ} \mathrm{C}$ and $30^{\circ} \mathrm{C}$. In particular, no significant differences $(p>0.05)$ or a decreasing trend $(p<0.05)$ in DPPH radical scavenging activity were observed in the white-fleshed and red-fleshed wines, respectively.

Along with the above evidence, $25^{\circ} \mathrm{C}$ could again be confirmed as the optimum temperature for the wine fermentation with high antioxidant content and activity. This might be due to the change in optimum temperature for the growth of Saccharomyces cerevisiae yeast when ethanol was gradually produced in wine. As reported by Van Uden and da Cruz Duarte (1981), although $S$. cerevisiae had an initial optimum growth temperature of $37^{\circ} \mathrm{C}$, it became most active at $25^{\circ} \mathrm{C}$ when the ethanol concentration reached $6 \%$ or higher. Therefore, at this temperature, the conversions of complex compounds into antioxidant substances might be most efficient, resulting in the highest scavenging capacity of the samples. In addition, the results showed that the addition of peel increased the antioxidant capacity of wine for both white-fleshed and red-fleshed species (up to $8 \%$ ) with the more obvious differences observed for the white-fleshed. This circumstance was in accordance with a report by Nurliyana et al. (2010), which revealed that the antioxidant activities of the $H$. undatus peel were nearly $30 \%$ higher than those of the H. polyrhizus peel.

\section{Consumer acceptability of dragon fruit wines}

Table 5 presents the sensory results using hedonic tests to evaluate the consumer acceptability of the wine products. The scores for appearance ranged from 2.825 to 4.325 . With a natural appealing red color, the red-fleshed species predictably received a higher assessment $(p<0.05)$ than the white-fleshed ones, with no differentiation in the peel inclusion $(p>0.05)$. Meanwhile, the addition of peel in the white-fleshed dragon fruit wine seemed to significantly $(p<0.05)$ enhance the visibility of the product. In judgment of aroma, it appeared that the panelists had a tendency to prefer the aroma from the wine of the white-fleshed with peel and red-fleshed species to the white-fleshed wine, although the mean values showed that all samples were in the upper or "like" zone from the neutral point (3.225 to 3.675). Both taste (3.450 to 3.800) and overall acceptability (3.025 to 3.400$)$ attributes expressed no distinction $(p>0.05)$ amongst all 4 samples, of which the mean values showed a general liking of the products. This implies that the addition of peel to the samples or difference in species did not significantly $(p>0.05)$ affect consumer acceptability of dragon fruit wine. With these results, peel utilization in dragon fruit wines is promising since it not only noticeably enhanced the nutritive values of the products but also improved the sensorial properties (in terms of appearance and aroma), especially for the whitefleshed species.

Table 5. Mean scores for 5-point hedonic test of the wine samples fermented at $25^{\circ} \mathrm{C}$

\begin{tabular}{lcccc}
\hline \multirow{2}{*}{ Attributes } & \multicolumn{3}{c}{ Types of wine } \\
\cline { 2 - 5 } & white-fleshed & white-fleshed with peel & red-fleshed & red-fleshed with peel \\
\hline Appearance & $2.825 \pm 0.931^{\mathrm{a}}$ & $3.450 \pm 0.959^{\mathrm{b}}$ & $4.325 \pm 0.917^{\mathrm{c}}$ & $4.125 \pm 0.791^{\mathrm{c}}$ \\
Aroma & $3.225 \pm 1.050^{\mathrm{a}}$ & $3.400 \pm 0.955^{\mathrm{a}, \mathrm{b}}$ & $3.625 \pm 0.868^{\mathrm{a}, \mathrm{b}}$ & $3.675 \pm 1.095^{\mathrm{b}}$ \\
Taste & $3.700 \pm 1.091^{\mathrm{a}}$ & $3.550 \pm 1.091^{\mathrm{a}}$ & $3.450 \pm 1.312^{\mathrm{a}}$ & $3.800 \pm 1.038^{\mathrm{a}}$ \\
Overall acceptability & $3.375 \pm 0.838^{\mathrm{a}}$ & $3.025 \pm 0.974^{\mathrm{a}}$ & $3.400 \pm 1.008^{\mathrm{a}}$ & $3.275 \pm 0.960^{\mathrm{a}}$ \\
\hline
\end{tabular}

Data are expressed as mean \pm standard deviation $(n=40)$.

${ }^{a-c}$ The same superscript letters in the same row express that those values are not significantly different $(p>0.05)$. 


\section{CONCLUSION}

In this study, the antioxidant properties of dragon fruit wines made from the $H$. polyrhizus and $H$. undatus species were evaluated. The effects of peel addition and fermentation temperature were also investigated in-depth. The results indicate that the fermentation of dragon fruit musts increases the content of certain antioxidants (e.g., phenolics) and the antioxidant capacity in wine. The DPPHž scavenging activity, total phenolic, betacyanin, and vitamin $\mathrm{C}$ contents were higher in the juice and wine prepared from the H. polyrhizus species than in those of the $H$. undatus species. The addition of dragon fruit peel in its winemaking had the advantages of higher antioxidant content and activity in the wine if a suitable fermentation temperature was chosen. In addition, the peel inclusion could also potentially improve the color and aroma of the products while still receiving similar overall acceptability from consumers.

\section{REFERENCES}

Adetuyi, F., Ibrahim, T. (2014). Effect of fermentation time on the phenolic, flavonoid and vitamin $\mathrm{C}$ contents and antioxidant activities of okra (Abelmoschus esculentus) seeds. Niger. Food J., 32, 128-137. https://doi. org/10.1016/S0189-7241(15)30128-4

Azeredo, H. (2009). Betalains: properties, sources, applications, and stability-a review. Int. J. Food Sci. Technol., 44, 2365-2376. https://doi.org/10.1111/ j.1365-2621.2007.01668.x

Barril, C., Rutledge, D. N., Scollary, G. R., Clark, A. C. (2016). Ascorbic acid and white wine production: a review of beneficial versus detrimental impacts. Aust. J. Grape Wine Res., 22, 169-181. https://doi.org/10.1111/ ajgw. 12207

Beltran, G., Novo, M., Leberre, V., Sokol, S., Labourdette, D., Guillamon, J. M., ..., Rozes, N. (2006). Integration of transcriptomic and metabolic analyses for understanding the global responses of low-temperature winemaking fermentations. FEMS Yeast Res., 6, 1167-1183. https://doi.org/10.1111/j.1567-1364.2006.00106.x

Bradshaw, M. P., Barril, C., Clark, A. C., Prenzler, P. D., Scollary, G. R. (2011) Ascorbic acid: a review of its chemistry and reactivity in relation to a wine environment. Crit. Rev. Food Sci. Nutr., 51, 479-498. https:// doi.org/10.1080/10408391003690559
Branduardi, P., Fossati, T., Sauer, M., Pagani, R., Mattanovich, D., Porro, D. (2007). Biosynthesis of vitamin $\mathrm{C}$ by yeast leads to increased stress resistance. PLoS One, 2, 10, 1092. https://doi.org/10.1371/journal. pone. 0001092

Choo, W. S., Yong, W. K. (2011). Antioxidant properties of two species of Hylocereus fruits. Adv. Appl. Sci. Res., 2, 418-425.

Derakhshan, Z., Ferrante, M., Tadi, M., Ansari, F., Heydari, A., Hosseini, M. S., ..., Sadrabad, E. K. (2018). Antioxidant activity and total phenolic content of ethanolic extract of pomegranate peels, juice and seeds. Food Chem. Toxicol., 114, 108-111. https://doi.org/10.1016/j. fct.2018.02.023

Foong, J. H., Hon, W. M., Ho, C. W. (2012). Bioactive compounds determination in fermented liquid dragon fruit (Hylocereus polyrhizus). Broneo Sci., 31, 38-56.

Herbach, K. M., Maier, C., Stintzing, F. C., Carle, R. (2007). Effects of processing and storage on juice colour and betacyanin stability of purple pitaya (Hylocereus polyrhizus) juice. Eur. Food Res. Technol., 224, 649-658. https://doi.org/10.1007/s00217-006-0354-5

Huang, P. H., Chen, Y. H., Tsai, H. Y., Chen, J. S., Wu, T. C., Lin, F. Y., ..., Lin, S. J. (2010). Intake of red wine increases the number and functional capacity of circulating endothelial progenitor cells by enhancing nitric oxide bioavailability. Arter. Thromb. Vasc. Biol., 30, 869-877. https://doi.org/10.1161/ATVBAHA.109.200618

Hur, S. J., Lee, S. Y., Kim, Y. C., Choi, I., Kim, G. B. (2014). Effect of fermentation on the antioxidant activity in plant-based foods. Food Chem., 160, 346-356. https:// doi.org/10.1016/j.foodchem.2014.03.112

Jagtap, U. B., Bapat, V. A. (2015). Phenolic composition and antioxidant capacity of wine prepared from custard apple (Annona squamosa L.) fruits. J. Food Process. Preserv., 39, 175-182. https://doi.org/10.1111/jfpp.12219

Kalaycığlu, Z., Erim, F. B. (2017). Total phenolic contents, antioxidant activities, and bioactive ingredients of juices from pomegranate cultivars worldwide. Food Chem., 221, 496-507. https://doi.org/10.1016/j.foodchem.2016.10.084

Kapur, A., Hasković, A., Čopra-Janićijević, A., Klepo, L., Topčagić, A., Tahirović, I., Sofić, E. (2012). Spectrophotometric analysis of total ascorbic acid content in various fruits and vegetables. Bull. Chem. Technol. Bosnia Herzegovina, 38, 39-42.

Kumar, S. B., Issac, R., Prabha, M. L. (2018). Functional and health-promoting bioactivities of dragon fruit. Drug Invent. Today, 10, 3307-3310. 
Le, T. T. H., Le, N. L. (2021). The impacts of peel inclusion and fermentation temperature on the bioactive compounds, antioxidant activity, and sensory properties of dragon fruit wines. Acta Sci. Pol. Technol. Aliment., 20(3), 337-346. http://dx.doi.org/10.17306/ J.AFS.2021.0907

Lagha-Benamrouche, S., Benaissa, T., Sadoudi, R. (2018). Desamerization of bitter jam: Biochemical and sensory quality. J. Food Qual., 2018, 1-13. https://doi. org/10.1155/2018/8178059

Limmongkon, A., Janhom, P., Amthong, A., Kawpanuk, M., Nopprang, P., Poohadsuan, J., ..., Srikummool, M. (2017). Antioxidant activity, total phenolic, and resveratrol content in five cultivars of peanut sprouts. Asian Pac. J. Trop. Biomed., 7, 332-338. https://doi.org/10.1016/j. apjtb.2017.01.002

Liu, S., Marsol-Vall, A., Laaksonen, O., Kortesniemi, M., Yang, B. (2020). Characterization and quantification of nonanthocyanin phenolic compounds in white and blue bilberry (Vaccinium myrtillus) juices and wines using UHPLC-DAD-ESI-QTOF-MS and UHPLC-DAD. J. Agric. Food Chem., 68, 7734-7744. https://pubs.acs. org/doi/abs/10.1021/acs.jafc.0c02842

Lourith, N., Kanlayavattanakul, M. (2013). Antioxidant and stability of dragon fruit peel colour. Agro Food Ind. Hi-Tech, 24, 56-58.

Luo, H., Cai, Y., Peng, Z., Liu, T., Yang, S. (2014). Chemical composition and in vitro evaluation of the cytotoxic and antioxidant activities of supercritical carbon dioxide extracts of pitaya (dragon fruit) peel. Chem. Cent. J., 8, 1-7. https://doi.org/10.1186/1752-153X-8-1

Makris, D. P., Kallithraka, S., Kefalas, P. (2006). Flavonols in grapes, grape products and wines: Burden, profile and influential parameters. J. Food Compos. Anal., 19, 396404. https://doi.org/10.1016/j.jfca.2005.10.003

Manihuruk, F. M., Suryati, T., Arief, I. I. (2017). Effectiveness of the red dragon fruit (Hylocereus polyrhizus) peel extract as the colorant, antioxidant, and antimicrobial on beef sausage. Media Peternakan., 40, 1, 47-54. https:// doi.org/10.5398/medpet.2017.40.1.47

Najgebauer-Lejko, D., Sady, M. (2015). Estimation of the antioxidant activity of the commercially available fermented milks. Acta Sci. Pol. Technol. Aliment., 14(4), 387-396. https://doi.org/10.17306/J.AFS.2015.4.38

Nguyen, M. P. (2014). Various factors influencing to red dragon fruit (Hylocereus polyrhizus) wine fermentation. Int. J. Multidiscip. Res. Dev., 1, 94-98.

Nurliyana, R., Syed Zahir, I., Mustapha Suleiman, K., Aisyah, M. R., Kamarul Rahim, K. (2010). Antioxidant study of pulp and peel of dragon fruits: A comparative study. Int. Food Res. J., 17, 367-375.

Olaniran, A. O., Maharaj, Y. R., Pillay, B. (2011). Effects of fermentation temperature on the composition of beer volatile compounds, organoleptic quality and spent yeast density. Electron. J. Biotechn., 14, 5-5.
Qian, S., Fang, X., Dan, D., Diao, E., Lu, Z. (2018). Ultrasonic-assisted enzymatic extraction of a water soluble polysaccharide from dragon fruit peel and its antioxidant activity. RSC Adv., 8, 42145-42152. https://doi. org/10.1039/C8RA06449K

Sari, A. R., Hardiyanti, R. (2013). Antioxidant level and sensory of dragon fruit (Hylocereus undatus) peel tea infusion made by partially fermented process. Agroind. J., 2, 63 .

Schwinn, M., Durner, D., Wacker, M., Delgado, A., Fischer, U. (2019). Impact of fermentation temperature on required heat dissipation, growth and viability of yeast, on sensory characteristics and on the formation of volatiles in Riesling. Aust. J. Grape Wine Res., 25, 173-184. https://doi.org/10.1111/ajgw.12386

Siow, L. F., Wong, Y. M. (2017). Effect of juice concentration on storage stability, betacyanin degradation kinetics, and sensory acceptance of red-fleshed dragon fruit (Hylocereus polyrhizus) juice. Int. J. Food Prop., 20, 623-632. https://doi.org/10.1080/10942912.2016.1172 086

Sun, B., Spranger, I., Yang, J., Leandro, C. O., Guo, L., Canário, S., ..., Wu, C. (2009). Red wine phenolic complexes and their in vitro antioxidant activity. J. Agric. Food Chem., 57, 8623-8627. https://doi.org/10.1021/ jf901610h

Taganas, W. R., Rosario, R. M. D., Palmes, N. D. (2015). Total flavonoids, total phenolics and vitamin C: Indicators of the antioxidant potentials of selected fruit peels. Int. J. Adv. Sci. Eng. Technol., 6, 161-164.

Truong, N., Dang, Q. T. (2016). Application of hydrolytic enzymes for improvement of red dragon fruit juice processing. Asia Pac. J. Sust. Agric. Food Energ., 4, 1-4.

Van Uden N., da Cruz Duarte, H. (1981). Effects of ethanol on the temperature profile of Saccharomyces cerevisiae. Z. Allg. Mikrobiol., 21, 10, 743-750. https://doi. org/10.1002/jobm.19810211006

Vie, A., Gulli, D., O`Mahony, M. (1991). Alternative hedonic measures. J. Food Sci., 56, 1-5. https://doi. org/10.1111/j.1365-2621.1991.tb07960.x

Wang, X. J., Li, Y. K., Song, H. C., Tao, Y. S., Russo, N. (2020). Phenolic matrix effect on aroma formation of terpenes during simulated wine fermentation - Part I: Phenolic acids. Food Chem., 341, 128288. https://doi. org/10.1016/j.foodchem.2020.128288

Woo, K. K., Wong, F. F., Chua, H. C., Tang, P. (2011). Stability of the spray-dried pigment of red dragon fruit [Hylocereus polyrhizus (Weber) Britton and Rose] as a function of organic acid additives and storage conditions. Philipp. Agric. Sci., 94, 264-269. 
Le, T. T. H., Le, N. L. (2021). The impacts of peel inclusion and fermentation temperature on the bioactive compounds, antioxidant activity, and sensory properties of dragon fruit wines. Acta Sci. Pol. Technol. Aliment., 20(3), 337-346. http://dx.doi.org/10.17306/ J.AFS.2021.0907

Wybraniec, S., Mizrahi, Y. (2005). Generation of decarboxylated and dehydrogenated betacyanins in thermally treated purified fruit extract from purple pitaya (Hylocereus polyrhizus) monitored by LC-MS/MS. J. Agric. Food Chem., 53, 6704-6712. https://doi.org/10.1021/ jf050700t
Zafrilla, P., Morillas, J., Mulero, J., Cayuela, J. M., Martínez-Cachá, A., Pardo, F., López Nicolás, J. M. (2003). Changes during storage in conventional and ecological wine: phenolic content and antioxidant activity. J. Agric. Food Chem., 51, 4694-4700. https://doi.org/10.1021/ jf021251p 